\title{
UNCERTAINTY ANALYSIS OF MEASURING SYSTEM FOR INSTANTANEOUS POWER RESEARCH
}

\section{Ariel Dzwonkowski, Leon Swędrowski}

Gdansk University of Technology, Faculty of Electrical and Control Engineering, ul. Narutowicza 11/12, 80-233 Gdansk, Poland (a.dzwonkowski@ely.pg.gda.pl, +48 5834717 78,هl.swedrowski@ely.pg.gda.pl, +48 5834717 26)

\begin{abstract}
The electrical power drawn by an induction motor is distorted in case of appearance of a certain type of failures. Under spectral analysis of the instantaneous power one obtains the components which are connected with definite types of damage. An analysis of the amplitudes and frequencies of the components allows to recognize the type of fault.

The paper presents a metrological analysis of the measurement system used for diagnosis of induction motor bearings, based on the analysis of the instantaneous power.

This system was implemented as a set of devices with dedicated software installed on a PC. A number of measurements for uncertainty estimation was carried out. The results of the measurements are presented in the paper. The results of the aforementioned analysis helped to determine the measurement uncertainty which can be expected during bearing diagnostic measurements, by the method relying on measurement and analysis of the instantaneous power of an induction machine.
\end{abstract}

Keywords: measuring system, metrological analysis, power measurements, measurement uncertainty, induction motor diagnostics.

(C) 2012 Polish Academy of Sciences. All rights reserved

\section{Introduction}

Diagnostics of electric machines allows to assess the technical condition of a machine without the necessity for its disassembly, through analysis of diagnostic signals generated by the machine and their comparison with reference signals. Due to the fact that the majority of failures in electric motors is caused by bearing damage, one can observe a particularly dynamic development in this area of diagnostics [1-4].

There are various methods for bearing diagnosis. The most commonly used ones are based on vibration measurement. However, those methods cannot be used in the absence of direct access to the engine. In such cases, the diagnosis is possible based on the measurement and analysis of the values of the engine power supply. In this manner, converters can be mounted on the electric cable supplying the engine which is situated away from the machine. The diagnostics is possible as the bearing damages generate an additional component in the spectrum of motor current [5-8]. Furthermore, the waveform of the instantaneous values of the power is deformed.

In this way, one of the possible diagnostic symptoms is the instantaneous power consumed by the motor. The measuring system designed for investigation of instantaneous power is presented in this article. Fig. 1 illustrates the block diagram of the system.

Due to the fact that the expected diagnostic components in the power signal have low values [5] in comparison with other components of this signal, their own noise should be small and the measuring system has to be highly accurate. While designing the system, 
particular attention was paid to these characteristics and the finished system was subjected to thorough examination.

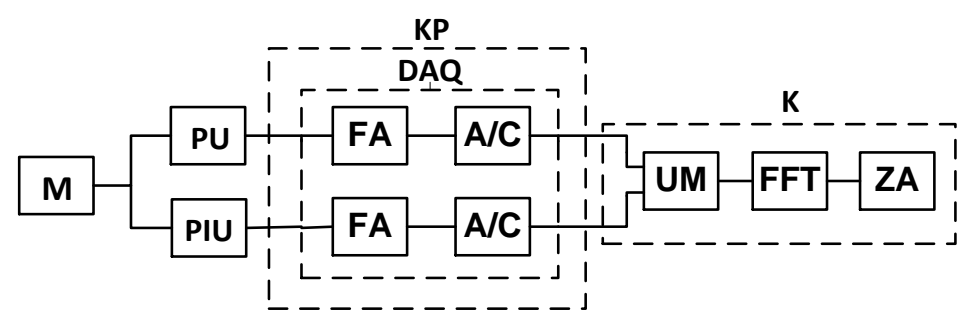

Fig. 1. Block diagram of the system for measuring instantaneous power in diagnostics of induction motor bearings, where: M - tested machine, PU - voltage converter, PIU - current-voltage converter, KP - measurement cage, DAQ - data acquisition card NI PXI 4462, FA - anti-aliasing filter, A/C - analogdigital converter, $\mathrm{K}$ - PC computer with software, UM - programme module multiplying current and voltage, FFT - programme module calculating the Fourier transform, ZA - programme module for instantaneous power analysis.

The subject of this article is a metrological analysis of the system designed for measuring instantaneous values of active power in diagnostics of induction motor bearings.

\section{Metrological analysis of the measuring system}

This chapter presents the metrological analysis of the measuring system used in the research.

The purpose of the metrological analysis of the system for measuring instantaneous power was to assess the uncertainty of measurements performed with the use of this system. The measuring system consisting of a FLUKE 5500A calibrator and a Keithley 2002 multimeter was used to assess the uncertainty of the measuring system consisting of a CV 3-500 voltage converter and a CT-5T current-voltage converter.

The results of these analyses will allow to define the measurement uncertainty which can be expected while performing diagnostic research of induction motor bearings, using the method of instantaneous power measurement and analysis in certain conditions at a test stand.

In the measuring system used for instantaneous power measurements, the measurement function is presented by the following formula:

$$
p(t)=u(t) \cdot i(t)
$$

As the measurement of instantaneous power is an indirect one [9-11], the uncertainty $u(p)$, assuming no correlation between the uncertainties of measured values, is defined by the following dependence:

$$
u(p)=\sqrt{\left(\frac{\partial p}{\partial u}\right) u^{2}(u)+\left(\frac{\partial p}{\partial i}\right) u^{2}(i)},
$$

where: $u(p)$ - uncertainty of instantaneous power measurement, $u^{2}(u)$ - voltage measurement variance, $u^{2}(i)$ - current measurement variance.

In accordance with formula (2), it is necessary to determine voltage measurement variance $u^{2}(u)$ and current measurement variance $u^{2}(i)$ in order to determine the uncertainty of instantaneous power measurement $u(p)$.

The procedure which has to be followed while determining these variances is presented in Fig. 2. 
The variance of measurement card indication correction $u^{2}\left(u_{1}\right)$ and the variance of voltage converter ratio estimation $u^{2}\left(k_{1}\right)$, have to be assessed in order to determine the voltage measurement variance $u^{2}(u)$. To define the $u^{2}\left(k_{1}\right)$ variance, it is necessary to assess the following:

- variance of standard output voltage value $-u_{2}^{2}$,

- voltage measurement variance resulting from scatter of results measured with a multimeter $-u_{3}^{2}$

- variance resulting from the limiting error of the multimeter $-u_{4}^{2}$.

To define the current measurement variance $u^{2}(i)$, it is necessary to take into consideration the variance of measurement card indication correction $u^{2}\left(u_{1}\right)$ and to determine the variance of current-voltage converter ratio estimation $u^{2}\left(k_{2}\right)$. In order to assess the $u^{2}\left(k_{2}\right)$ variance, it is necessary to define the following:

- variance of standard output current value $-u_{5}{ }^{2}$,

- voltage measurement variance resulting from scatter of results measured with the multimeter $-u_{6}^{2}$,

- variance resulting from the limiting error of the multimeter $-u_{7}^{2}$.

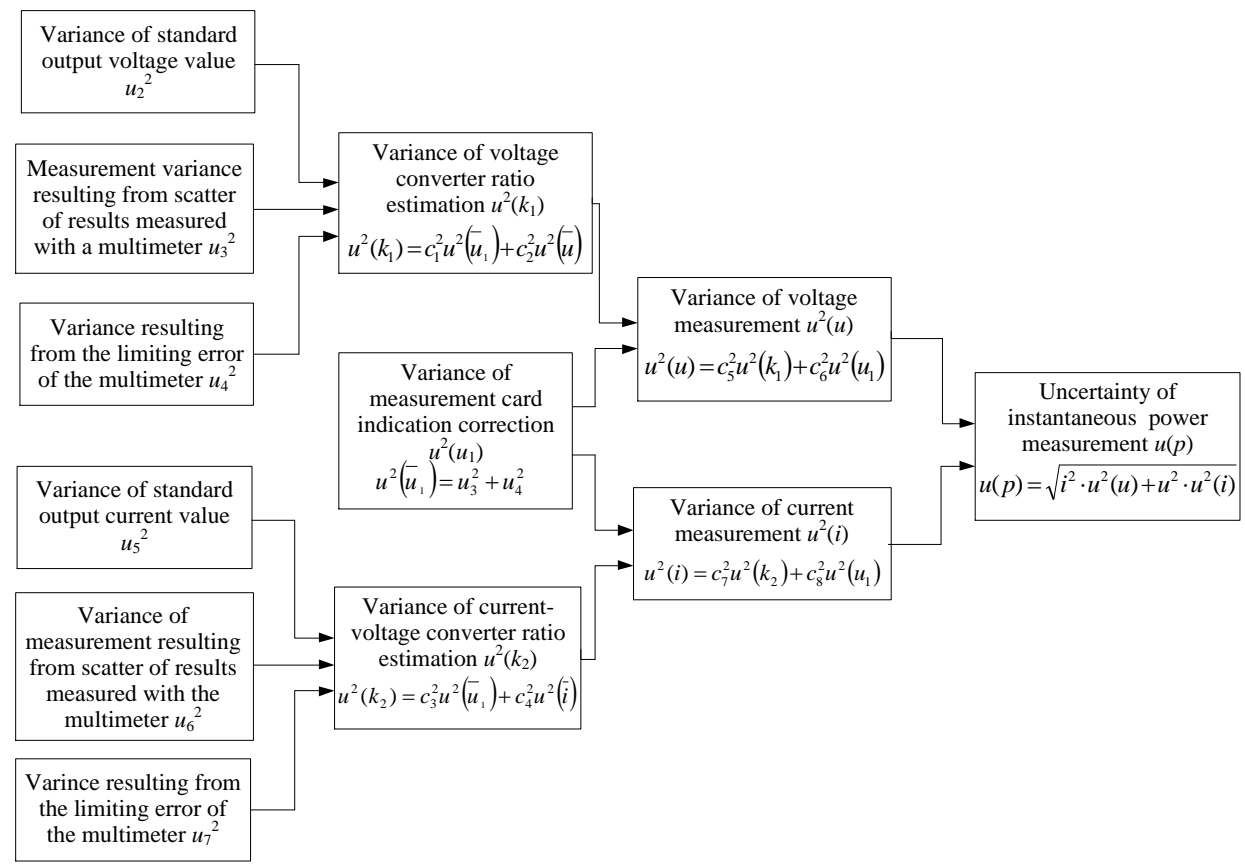

Fig. 2. Procedure to be followed while determining uncertainty of instantaneous power measurement $u(p)$ in a measuring system with voltage-voltage and current-voltage converters; $c_{1}, c_{2}, c_{3}, c_{4}, c_{5}, c_{6}, c_{7}, c_{8}$ - sensitivity coefficients.

The next subsection of this chapter presents the methodology for assessing values of the variances listed above in a measuring system with a voltage converter and a current-voltage converter.

\subsection{Uncertainty of voltage measurement}

The output voltage of a voltage converter is defined by the following dependence:

$$
u_{1}=k_{1} \cdot u,
$$

where: $u_{1}$ - output voltage of voltage converter, $k_{1}$ - ratio of voltage converter, $u$ - input voltage of voltage converter. 
The converter was tested for a number of frequencies and a few input voltage values in order to assess the uncertainty of voltage measurement. In the measuring system, a voltage value is defined by the measurement function which constitutes the basis for assessment of voltage measurement uncertainty.

The voltage measurement variance $u^{2}(u)$ is defined by the following dependence [9 - 11]:

$$
u^{2}(u)=\left(\frac{\partial u}{\partial k_{1}}\right)^{2} u^{2}\left(k_{1}\right)+\left(\frac{\partial u}{\partial u_{1}}\right)^{2} u^{2}\left(u_{1}\right)
$$

where: $u^{2}\left(k_{1}\right)$ - variance of voltage converter ratio estimation, $u^{2}\left(u_{1}\right)$ - variance of measuring voltage with a data acquisition card.

\subsubsection{Variance of voltage converter ratio estimation}

The variance of voltage converter ratio estimation can be written as follows:

$$
u^{2}\left(k_{1}\right)=\left(\frac{\partial k_{1}}{\partial u_{1}}\right)^{2} u^{2}\left(\bar{u}_{1}\right)+\left(\frac{\partial k_{1}}{\partial u}\right)^{2} u^{2}(\bar{u}),
$$

where: $u^{2}\left(k_{1}\right)$ - variance of voltage converter ratio estimation, $u^{2}\left(\bar{u}_{1}\right)$ - variance of average voltage value, measured with the Keithley 2002 multimeter, $u^{2}(\bar{u})$ - variance of the average value of the voltage connected to the converter input.

The variance of average output voltage value of the converter $-u^{2}\left(\bar{u}_{1}\right)$ is closely related to measurement uncertainty of the Keithley multimeter and defined by the following dependence [9-11]:

$$
u^{2}\left(\bar{u}_{1}\right)=u_{3}^{2}+u_{4}^{2}
$$

where: $u_{3}$ - measurement uncertainty resulting from scatter of results measured with the Keithley 2002 multimeter, $u_{4}$ - uncertainty resulting from the limitation error of the Keithley 2002 multimeter, presented in the specification by the producer.

In the conducted research, the Fluke 5500A calibrator generated the input signal for the converter. The variance of the average value of voltage connected to the converter input $u^{2}(\bar{u})$ is presented by the following formula:

$$
u^{2}(\bar{u})=u_{2}^{2}
$$

where: $u_{2}^{2}$ - variance of the output voltage value in the Fluke 5500A calibrator, presented in the specification by the producer.

The abovementioned tested converter was the type CV 3-500 LEM converter. The tests were done for 6 frequency values: $50 \mathrm{~Hz}, 75 \mathrm{~Hz}, 90 \mathrm{~Hz}, 120 \mathrm{~Hz}, 500 \mathrm{~Hz}, 1000 \mathrm{~Hz}$; for each of them at 6 different voltage values: $20 \mathrm{~V}, 50 \mathrm{~V}, 100 \mathrm{~V}, 150 \mathrm{~V}, 200 \mathrm{~V}, 230 \mathrm{~V}$. The measurements were repeated 50 times. The components were calculated for each variant, in accordance with formula (5), (6) and (7). Table 1 presents the maximal obtained values of variance components.

Based on the assessed variances, we can observe that the ratio of voltage converter for frequencies of $120 \mathrm{~Hz}, 500 \mathrm{~Hz}$ and $1000 \mathrm{~Hz}$ is characterized by the lowest uncertainty value. In contrast, this uncertainty reaches its highest value for the frequency of the power network, 
i.e. $50 \mathrm{~Hz}$. The main component of the uncertainty value for the frequency of $50 \mathrm{~Hz}$ is the measurement uncertainty resulting from the scatter of results measured with a multimeter.

Table 1. Maximal values of variance components for each of the frequencies.

\begin{tabular}{|c|c|c|c|c|c|c|c||}
\hline \multirow{2}{*}{$\begin{array}{c}\text { Quantity } \\
\text { symbol }\end{array}$} & $\begin{array}{c}\text { Distribution of } \\
\text { probability }\end{array}$ & \multicolumn{5}{|c||}{ Maximal variance components for individual frequencies } \\
\cline { 3 - 9 } & $50 \mathrm{~Hz}$ & $75 \mathrm{~Hz}$ & $90 \mathrm{~Hz}$ & $120 \mathrm{~Hz}$ & $500 \mathrm{~Hz}$ & $1000 \mathrm{~Hz}$ \\
\hline \hline$u_{3}{ }^{2}\left[\mathrm{~V}^{2}\right]$ & normal & $1.21 \mathrm{E}-8$ & $2.93 \mathrm{E}-10$ & $4.57 \mathrm{E}-10$ & $4.82 \mathrm{E}-10$ & $1.57 \mathrm{E}-8$ & $6.47 \mathrm{E}-8$ \\
\hline$u_{4}{ }^{2}\left[\mathrm{~V}^{2}\right]$ & rectangular & $9.67 \mathrm{E}-6$ & $9.67 \mathrm{E}-6$ & $9.67 \mathrm{E}-6$ & $4.80 \mathrm{E}-6$ & $4.80 \mathrm{E}-6$ & $4.80 \mathrm{E}-6$ \\
\hline$u_{2}{ }^{2}\left[\mathrm{~V}^{2}\right]$ & rectangular & $3.70 \mathrm{E}-3$ & $3.70 \mathrm{E}-3$ & $3.70 \mathrm{E}-3$ & $3.70 \mathrm{E}-3$ & $3.70 \mathrm{E}-3$ & $3.70 \mathrm{E}-3$ \\
\hline$u^{2}\left(k_{1}\right)\left[\mathrm{V}^{2} / \mathrm{V}^{2}\right]$ & normal & $2.79 \mathrm{E}-8$ & $2.79 \mathrm{E}-8$ & $2.79 \mathrm{E}-8$ & $1.58 \mathrm{E}-8$ & $1.57 \mathrm{E}-8$ & $1.59 \mathrm{E}-8$ \\
\hline \hline
\end{tabular}

\subsection{Variance of voltage measurement performed with a data acquisition card}

It was assumed that the variance of voltage measurement performed with a data acquisition card $-u^{2}\left(u_{1}\right)$ is equal to the variance of voltage measurement correction $-u^{2}\left(\Delta u_{8}\right)$.

The estimation of variance of voltage measurement correction with the data acquisition card was defined from the following dependence:

$$
u^{2}\left(\Delta u_{8}\right)=u_{9}^{2}+u_{10}^{2}+u_{2}^{2}
$$

where: $u^{2}\left(\Delta u_{8}\right)$ - variance of determining the correction of measurement card indication, $u_{9}^{2}$ - variance resulting from scatter of measurement results obtained with a data acquisition card, $u_{10}^{2}$ - variance resulting from resolution of measurement card indication, $u_{2}^{2}$ - variance of the output voltage value in the Fluke 5500A calibrator.

In the conducted research, we used the NI PXI 1031 measurement cage, in which the NI PXI 4462 measurement card had been installed. The measurements were repeated 50 times for each of the voltage values set in the standard: $0.3 \mathrm{~V}, 0.5 \mathrm{~V}, 1 \mathrm{~V}, 2 \mathrm{~V}, 3 \mathrm{~V}, 5 \mathrm{~V}$, and at 6 frequency values (identical to those used for the voltage converter) for each of the voltage values.

For each of the combinations of voltage and frequency, the variance components were calculated in accordance with formula (8). Table 2 presents maximal obtained values of variance components (the variance of measuring voltage with the data acquisition card) for each of the frequencies.

For measurements of voltage using the data acquisition card, it was assumed that the variance of the voltage is equal to the variance of the designation of the amendment to indicate the measurement card:

$$
u^{2}\left(u_{1}\right)=u^{2}\left(\Delta u_{8}\right)
$$

where: $u^{2}\left(u_{1}\right)$ - variance of voltage measurement performed with the data acquisition card.

Table 2. Maximal values of variance components for individual frequencies.

\begin{tabular}{|c|c|c|c|c|c|c|c|}
\hline \multirow{2}{*}{$\begin{array}{c}\text { Quantity } \\
\text { symbol }\end{array}$} & \multirow{2}{*}{$\begin{array}{c}\text { Distribution } \\
\text { probability }\end{array}$} & \multicolumn{6}{|c|}{ Maximal variance components for individual frequencies } \\
\cline { 3 - 8 } & $50 \mathrm{~Hz}$ & $75 \mathrm{~Hz}$ & $90 \mathrm{~Hz}$ & $120 \mathrm{~Hz}$ & $500 \mathrm{~Hz}$ & $1000 \mathrm{~Hz}$ \\
\hline \hline$u^{2}{ }_{10}\left[\mathrm{~V}^{2}\right]$ & rectangular & $3.55 \mathrm{E}-13$ & $3.55 \mathrm{E}-13$ & $3.5 \mathrm{E}-13$ & $3.55 \mathrm{E}-13$ & $3.55 \mathrm{E}-13$ & $3.55 \mathrm{E}-13$ \\
\hline$u^{2}{ }_{9}\left[\mathrm{~V}^{2}\right]$ & normal & $3.42 \mathrm{E}-7$ & $2.47 \mathrm{E}-9$ & $2.83 \mathrm{E}-9$ & $2.19 \mathrm{E}-9$ & $2.13 \mathrm{E}-9$ & $2.30 \mathrm{E}-9$ \\
\hline$u_{2^{2}}\left[\mathrm{~V}^{2}\right]$ & rectangular & $1.69 \mathrm{E}-6$ & $1.69 \mathrm{E}-6$ & $1.69 \mathrm{E}-6$ & $1.69 \mathrm{E}-6$ & $1.69 \mathrm{E}-6$ & $1.69 \mathrm{E}-6$ \\
\hline$u^{2}\left(\Delta u_{8}\right)\left[\mathrm{V}^{2}\right]$ & normal & $1.69 \mathrm{E}-6$ & $1.69 \mathrm{E}-6$ & $1.69 \mathrm{E}-6$ & $1.69 \mathrm{E}-6$ & $1.69 \mathrm{E}-6$ & $1.69 \mathrm{E}-6$ \\
\hline
\end{tabular}


Based on the obtained results, it can be observed that the uncertainty of standard correction is the main component of uncertainty value related to measuring voltage with the data acquisition card. The $u_{2}^{2}$ value is greater by a few ranges of value than the remaining components of uncertainty of voltage measurements performed with the data acquisition card.

\subsection{Complex variance of voltage estimation}

The complex variance of voltage estimation $-u^{2}(u)$ was calculated in accordance with dependence (4). Table 3 presents sample calculation results regarding the complex uncertainty of voltage measurements, for the power network frequency of $50 \mathrm{~Hz}$.

Table 3. Budget of voltage estimate uncertainty for the frequency of $50 \mathrm{~Hz}$.

\begin{tabular}{|l|c|c|c|c|c|}
\hline $\begin{array}{c}\text { Quantity } \\
x_{i}\end{array}$ & $\begin{array}{c}\text { Quantity } \\
\text { estimate } \\
x_{i}\end{array}$ & $\begin{array}{c}\text { Standard variance } \\
u^{2}\left(x_{i}\right)\end{array}$ & $\begin{array}{c}\text { Distribution of } \\
\text { probability }\end{array}$ & $\begin{array}{c}\text { Sensitivity } \\
\text { coefficient } \\
c_{i}\end{array}$ & $\begin{array}{c}\text { Share in complex } \\
\text { variance } \\
u^{2}(y)\end{array}$ \\
\hline \hline$u_{1}$ & $4.60 \mathrm{~V}$ & $1.69 \mathrm{E}-6 \mathrm{~V}^{2}$ & normal & $50 \mathrm{~V} / \mathrm{V}$ & $2.31 \mathrm{E}+4 \mathrm{~V}^{2}$ \\
\hline$k_{1}$ & $0.02 \mathrm{~V} / \mathrm{V}$ & $1.75 \mathrm{E}-4 \mathrm{~V}^{2} / \mathrm{V}^{2}$ & normal & $11500 \mathrm{~V} 2 / \mathrm{V}$ & $6.76 \mathrm{E}-10 \mathrm{~V}^{2}$ \\
\hline$u$ & $230.00 \mathrm{~V}$ & & normal & & $6.23 \mathrm{E}-2 \mathrm{~V}^{2}$ \\
\hline \multicolumn{7}{|r|}{} & \multicolumn{2}{|c|}{ Standard uncertainty $u(u)$} & $0.25 \mathrm{~V}$ \\
\hline
\end{tabular}

With the confidence level assumed at $95 \%$ and the extension coefficient $k=2$, the extended uncertainty $U_{u}$ of voltage measurement can be determined from the following formula [9-11]:

$$
U_{u}=k \cdot u(u),
$$

where: $U_{u}$ - extended uncertainty of voltage measurement, $k$ - extension coefficient, $u(u)$ - complex variance of voltage estimation.

The extended uncertainty of voltage measurement for the frequency of $50 \mathrm{~Hz}$ is: $U_{u}=0.50 \mathrm{~V}$.

The budget of voltage estimate uncertainty for the frequency of $120 \mathrm{~Hz}$ is presented in Table 4.

Table 4. Budget of voltage estimate for frequency of $120 \mathrm{~Hz}$.

\begin{tabular}{|c|c|c|c|c|c|}
\hline $\begin{array}{c}\text { Quantity } \\
\qquad X_{i}\end{array}$ & $\begin{array}{c}\text { Quantity } \\
\text { estimate } \\
x_{i}\end{array}$ & $\begin{array}{c}\text { Standard variance } \\
\qquad u^{2}\left(x_{i}\right)\end{array}$ & $\begin{array}{c}\text { Distribution of } \\
\text { probability }\end{array}$ & $\begin{array}{c}\text { Sensitivity } \\
\text { coefficient } \\
\mathrm{Ci}_{i} \\
\end{array}$ & $\begin{array}{c}\text { Share in complex } \\
\text { variance } \\
u^{2}(y) \\
\end{array}$ \\
\hline$u_{1}$ & $4.60 \mathrm{~V}$ & 1.69E-6 V² & normal & $50 \mathrm{~V} / \mathrm{V}$ & $4.22 \mathrm{E}-3 \mathrm{~V}^{2}$ \\
\hline$k_{1}$ & 0.02 V/V & $3.56 \mathrm{E}-10 \mathrm{~V}^{2} / \mathrm{V}^{2}$ & normal & $11500 \mathrm{~V}^{2} / \mathrm{V}$ & $1.57 \mathrm{E}-2 \mathrm{~V}^{2}$ \\
\hline$u$ & $230.00 \mathrm{~V}$ & & normal & & $2.00 \mathrm{E}-2 \mathrm{~V}^{2}$ \\
\hline & & & \multicolumn{2}{|c|}{ Standard uncertainty $u(u)$} & $1.41 \mathrm{E}-1 \mathrm{~V}$ \\
\hline
\end{tabular}

The extended uncertainty of voltage measurement at the frequency of $120 \mathrm{~Hz}$ is: $U_{u}=2 \cdot 1.41 \cdot 10^{-1}=2.82 \cdot 10^{-1} \approx 0.28 \mathrm{~V}$.

Based on the performed calculations, the result of voltage measurement for the frequency of $50 \mathrm{~Hz}$, at the assumed confidence level and extension coefficient can be written down as: $U=(230.00 \pm 0.50) \mathrm{V}$.

The result of voltage measurement for the frequency of $120 \mathrm{~Hz}$, at the assumed confidence level and extension coefficient can be written down as: $U=(230.00 \pm 0.28) \mathrm{V}$. 
Comparing the values of extended uncertainty for the frequencies of $50 \mathrm{~Hz}$ and $120 \mathrm{~Hz}$, it can be stated that for the frequency of $50 \mathrm{~Hz}$ this level of uncertainty is higher than in the measurements performed for the frequency of $120 \mathrm{~Hz}$. These uncertainties do not exceed $1 \%$ of the value of the measured voltage.

\subsection{Uncertainty of current measurement}

In the measuring system, the current value is defined by the measurement function, which is the basis for assessment of current measurement uncertainty:

$$
i=\frac{u_{1}}{k_{2}}
$$

where: $u_{1}$ - output voltage of current-voltage converter, $k_{2}$ - ratio of current-voltage converter, $i$-input current of current-voltage converter.

The variance of current measurement is defined by the following dependence [9-11]:

$$
u^{2}(i)=\left(\frac{\partial i}{\partial k_{2}}\right)^{2} u^{2}\left(k_{2}\right)+\left(\frac{\partial i}{\partial u_{1}}\right)^{2} u^{2}\left(u_{1}\right)
$$

where: $u^{2}(i)$ - current measurement variance, $i$ - current measured at the input of the currentvoltage converter, $u^{2}\left(u_{1}\right)$ - variance of voltage measurement performed with the data acquisition card, $u^{2}\left(k_{2}\right)$ - variance of current-voltage converter ratio estimation.

The values of the assessed variances of uncertainty related to voltage measurement performed with the data acquisition card defined in p. 2.2, were substituted in the above dependence of variance values concerning voltage measurements performed with the data acquisition card $-u^{2}\left(u_{1}\right)$.

\subsubsection{Variance of current-voltage converter ratio estimation}

The variance of current-voltage converter ratio estimation is given as:

$$
u^{2}\left(k_{2}\right)=\left(\frac{\partial k_{2}}{\partial u_{1}}\right)^{2} u^{2}\left(\bar{u}_{1}\right)+\left(\frac{\partial k_{2}}{\partial i}\right)^{2} u^{2}(\bar{i}),
$$

where: $u^{2}\left(k_{2}\right)$ - variance of current-voltage converter ratio estimation, $u^{2}\left(\bar{u}_{1}\right)$ - variance of average output voltage value of the current-voltage converter, $u^{2}(\bar{i})$ - uncertainty of the average value of current connected to converter input.

The variance of average output voltage value of the current-voltage converter $-u^{2}\left(\bar{u}_{1}\right)$ is closely related to the measurement uncertainty of the Keithley 2002 multimeter and amounts to:

$$
u^{2}\left(\bar{u}_{1}\right)=u_{6}^{2}+u_{7}^{2},
$$

where: $\bar{u}_{1}$-average voltage value, measured with the Keithley 2002 multimeter, $u_{6}-$ measurement uncertainty resulting from scatter of results measured with the Keithley 2002 multimeter, $u_{7}$ - uncertainty resulting from limitation error of the Keithley 2002 multimeter, presented in the specification by the producer. 
In the research discussed here, the Fluke 5500A calibrator generated the input signal for the converter. The variance of the average value of current connected to the converter input $u^{2}(\bar{i})$ is presented by the following formula:

$$
u^{2}(\bar{i})=u_{5}^{2}
$$

where: $u_{5}$ - uncertainty of output current value of Fluke 5500A calibrator, presented in the specification by the producer.

The tests on the current-voltage converter type CT-5T were performed for 6 frequency values: $50 \mathrm{~Hz}, 75 \mathrm{~Hz}, 120 \mathrm{~Hz}, 250 \mathrm{~Hz}, 500 \mathrm{~Hz}, 1000 \mathrm{~Hz}$, at 6 different values of current intensity: $250 \mathrm{~mA}, 500 \mathrm{~mA}, 1 \mathrm{~A}, 1.9 \mathrm{~A}, 2.5 \mathrm{~A}, 2.9 \mathrm{~A}$, for each of these frequencies. The measurements were repeated 50 times. The components were calculated for each of the variants in accordance with formulae (13), (14) and (15). Table 5 presents the maximal values obtained of these components.

Table 5. Maximal values of variance components for individual frequencies.

\begin{tabular}{|c|c|c|c|c|c|c|c|}
\hline \hline \multirow{2}{*}{$\begin{array}{c}\text { Quantity } \\
\text { symbol }\end{array}$} & $\begin{array}{c}\text { Distribution of } \\
\text { probability }\end{array}$ & \multicolumn{5}{|c|}{ Maximal variance components for individual frequencies } \\
\cline { 3 - 8 } & $50 \mathrm{~Hz}$ & $75 \mathrm{~Hz}$ & $90 \mathrm{~Hz}$ & $120 \mathrm{~Hz}$ & $500 \mathrm{~Hz}$ & $1000 \mathrm{~Hz}$ \\
\hline \hline$u^{2}\left[\mathrm{~V}^{2}\right]$ & normal & $5.41 \mathrm{E}-5$ & $7.47 \mathrm{E}-5$ & $1.06 \mathrm{E}-4$ & $6.64 \mathrm{E}-5$ & $3.83 \mathrm{E}-5$ & $7.54 \mathrm{E}-5$ \\
\hline$u^{2}\left[\mathrm{~V}^{2}\right]$ & rectangular & $6.33 \mathrm{E}-6$ & $6.33 \mathrm{E}-6$ & $6.33 \mathrm{E}-6$ & $3.74 \mathrm{E}-6$ & $3.74 \mathrm{E}-6$ & $3.74 \mathrm{E}-6$ \\
\hline$u^{2}\left[\mathrm{~A}^{2}\right]$ & rectangular & $3.48 \mathrm{E}-7$ & $3.48 \mathrm{E}-7$ & $3.48 \mathrm{E}-7$ & $3.48 \mathrm{E}-7$ & $3.48 \mathrm{E}-7$ & $3.74 \mathrm{E}-6$ \\
\hline$u^{2}\left(k_{2}\right)\left[\mathrm{V}^{2} / \mathrm{A}^{2}\right]$ & normal & $7.22 \mathrm{E}-6$ & $9.68 \mathrm{E}-6$ & $1.34 \mathrm{E}-5$ & $8.38 \mathrm{E}-6$ & $5.05 \mathrm{E}-6$ & $9.46 \mathrm{E}-6$ \\
\hline
\end{tabular}

The above consideration shows that the main component of uncertainty related to currentvoltage converter ratio is the measurement uncertainty resulting from scatter of results measured with the Keithley 2002 multimeter.

\subsubsection{Complex variance of current estimate}

The complex variance of current estimate was calculated based on dependence (12). Sample calculation results for current measurement complex variance were obtained for two frequency values: $50 \mathrm{~Hz}$ and $120 \mathrm{~Hz}$. The uncertainty budget of current estimate for the frequency of $50 \mathrm{~Hz}$ is presented in Table 6 .

Table 6. Uncertainty budget of current estimate for the frequency of $50 \mathrm{~Hz}$.

\begin{tabular}{|c|c|c|c|c|c|}
\hline $\begin{array}{c}\text { Quantity } \\
X_{i}\end{array}$ & $\begin{array}{c}\text { Quantity } \\
\text { estimate } \\
x_{i}\end{array}$ & $\begin{array}{c}\text { Standard variance } \\
\qquad u^{2}\left(x_{i}\right)\end{array}$ & $\begin{array}{l}\text { Distribution of } \\
\text { probability }\end{array}$ & $\begin{array}{c}\text { Sensitivity } \\
\text { coefficient } \\
C_{i} \\
\end{array}$ & $\begin{array}{c}\text { Share in complex } \\
\text { variance } \\
u^{2} i(y) \\
\end{array}$ \\
\hline$u_{1}$ & $2.90 \mathrm{~V}$ & $1.69 \mathrm{E}-6 \mathrm{~V}^{2}$ & normal & $1 \mathrm{~A} / \mathrm{V}$ & $1.69 E-6 A^{2}$ \\
\hline$k_{2}$ & $1 \mathrm{~V} / \mathrm{A}$ & 7.22E-6 V2/A2 & normal & $2.9 \mathrm{~A}^{2} \mathrm{~N}$ & $6.07 E-5 A^{2}$ \\
\hline$i$ & $2.90 \mathrm{~A}$ & & normal & & $6.24 E-5 A^{2}$ \\
\hline & & & \multicolumn{2}{|c|}{ Standard uncertainty $u(i)$} & 7.90E-3 A \\
\hline
\end{tabular}

At the assumed confidence level equal to $95 \%$ and the extension coefficient $k=2$, the extended uncertainty $U_{i}$ of current measurement can be determined from the following dependence [9-11]:

$$
U_{i}=k \cdot u(i),
$$

where: $U_{i}$ - extended uncertainty of current measurement, $k$ - extension coefficient, $u(i)$ - complex variance of current estimation. 
Using formula (16), we calculated the extended uncertainty of current measurement at the frequency of $50 \mathrm{~Hz}$. This uncertainty amounts to: $U=2 \cdot 7.90 \cdot 10^{-3}=1.58 \cdot 10^{-2} \approx 0.02 \mathrm{~A}$.

The uncertainty budget of current estimate for the frequency of $120 \mathrm{~Hz}$ is presented in Table 7.

Table 7. Uncertainty budget of current estimate for the frequency of $120 \mathrm{~Hz}$.

\begin{tabular}{|l|c|c|c|c|c||}
\hline $\begin{array}{c}\text { Quantity } \\
x_{i}\end{array}$ & $\begin{array}{c}\text { Quantity estimate } \\
x_{i}\end{array}$ & $\begin{array}{c}\text { Standard variance } \\
u^{2}\left(x_{i}\right)\end{array}$ & $\begin{array}{c}\text { Distribution of } \\
\text { probability }\end{array}$ & $\begin{array}{c}\text { Sensitivity } \\
\text { coefficient } \\
c_{i}\end{array}$ & $\begin{array}{c}\text { Share in complex } \\
\text { variance } \\
u^{2}(y)\end{array}$ \\
\hline \hline$u_{1}$ & $2.90 \mathrm{~V}$ & $1.69 \mathrm{E}-6 \mathrm{~V}^{2}$ & normal & $1 \mathrm{~A} / \mathrm{V}$ & $1.69 \mathrm{E}-6 \mathrm{~A}^{2}$ \\
\hline$k_{2}$ & $1 \mathrm{~V} / \mathrm{A}$ & $8.38 \mathrm{E}-6 \mathrm{~V}^{2} / \mathrm{A}^{2}$ & normal & $2.9 \mathrm{~A}^{2} \mathrm{~V}$ & $7.05 \mathrm{E}-5 \mathrm{~A}^{2}$ \\
\hline$i$ & $2.90 \mathrm{~A}$ & & normal & $7.22 \mathrm{E}-5 \mathrm{~A}^{2}$ \\
\hline \multicolumn{7}{|r|}{} & \multicolumn{2}{|c|}{ Standard uncertainty $u(i)$} & $8.50 \mathrm{E}-3 \mathrm{~A}$ \\
\hline
\end{tabular}

The dependence (16) was used to assess the extended uncertainty. For the frequency of $120 \mathrm{~Hz}$, this uncertainty amounts to: $U=2 \cdot 8.50 \cdot 10^{-3}=1.70 \cdot 10^{-2} \approx 0.02 \mathrm{~A}$.

Based on the performed calculations, the result of current measurement for the frequency of $50 \mathrm{~Hz}$, at the assumed confidence level and sensitivity coefficient can be written down as: $I=(2.90 \pm 0.02) \mathrm{A}$.

Based on the performed calculations, the result of current measurement for the frequency of $120 \mathrm{~Hz}$, at the assumed confidence level and sensitivity coefficient can be written down as: $I=(2.90 \pm 0.02) \mathrm{A}$.

Comparing the values of extended uncertainty of current measurement for the frequencies of $50 \mathrm{~Hz}$ and $120 \mathrm{~Hz}$, it can be stated that these uncertainties do not exceed $5 \%$ of the value of the measured current.

\subsection{Uncertainty of instantaneous power measurement}

The uncertainty of instantaneous power measurement was calculated based on formula (2), i.e. the square root of the sum of voltage measurement variance $u^{2}(u)$ and current measurement variance $u^{2}(i)[9-11]$.

The standard uncertainty values of instantaneous power measurement for the same frequency values, at which the voltage-voltage and current-voltage converters were tested, are presented in the graph - Fig. 3 .

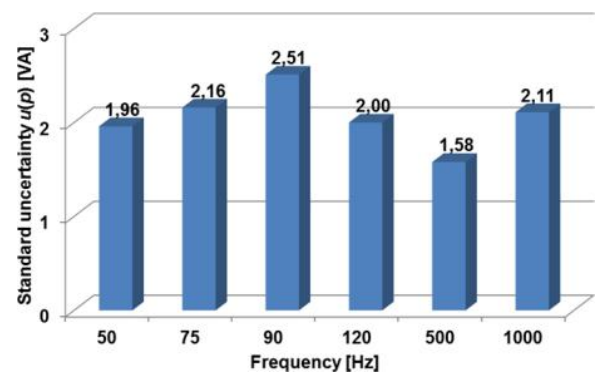

Fig. 3. Graph presenting the dependence of instantaneous power measurement uncertainty $u(p)$ on the frequency in the measuring system with voltage-voltage and current-voltage converters.

\section{Conclusions}

It can be inferred from the above results that the highest level of uncertainty in instantaneous power measurements is characteristic for the measurements performed at the 
frequency of $90 \mathrm{~Hz}$, while the lowest level - for the measurements at the frequency of $500 \mathrm{~Hz}$.

In both measurement lines, i.e. of voltage and current, the largest contribution to the uncertainty budget is made by current and voltage converters respectively. Between these two, the uncertainty of the current converter has a decidedly higher value - even five times higher at certain points.

The extended uncertainty $U_{p}$ of instantaneous power measurement was also assessed. This uncertainty was determined at the assumed confidence level of $95 \%$ and the extension coefficient $k=2$. For example, at the frequency of $50 \mathrm{~Hz}$, the uncertainty $U_{p}=3.92 \mathrm{VA}$, and at the frequency of $120 \mathrm{~Hz}-U_{p}=4.00 \mathrm{VA}$.

The uncertainty $U_{p}=3.92 \mathrm{VA}$ occurred for the frequency of $50 \mathrm{~Hz}$, the voltage value of $230 \mathrm{~V}$ and the current value of $2.9 \mathrm{~A}$. Therefore, a full notation of the result of instantaneous power measurement can be presented as: $p=(1014 \pm 4)$ VA. Thus, the uncertainty of an instantaneous power measurement system does not exceed $1 \%$ of the measured value of instantaneous power.

\section{Acknowledgements}

This work was supported by the Polish Ministry of Science and Higher Education (grant No. 2389/B/T02/2010/38).

\section{References}

[1] Bellini, A., Immovilli, F., Rubini, R., Tassoni, C. (2008). Diagnosis of bearing faults of induction machines by vibration or current signals: A critical comparison. IEEE Industry Applications Society Annual Meeting, 5-9, 1-8.

[2] Swędrowski, L. (2010) Current measurements and analysis for induction motor diagnostics. Metrol. Meas. Syst., 17(1), 87-94.

[3] Dzwonkowski, A., Swędrowski, L. (2010). Motor Bearing Diagnostics Performed by Means of Laser Vibrometer. In Proc. Conference SDEMPED 2011, 8th IEEE Symposium on Diagnostics for Electrical Machines, Power Electronics and Drives, Bologna, Italy, 1-5 [pdf].

[4] Swędrowski, L. (2010). Diagnostics of induction motor bearings - possibility of measurements. In Proc. Eighth International Conference on Condition Monitoring and Machinery Failure Prevention Technologies CM 2010. BINDT. 1-10 [pdf].

[5] Swędrowski, L., Rusek, J. (2009). Model and laboratory simulation of a induction motor for diagnostic purposes. Metrol. Meas. Syst., 16(4), 607-618.

[6] Bellini, A., Immovilli, F., Rubini, R., Tassoni, C. (2008), Diagnosis of bearing faults in induction machines by vibration or current signals: A critical comparison. Conf. Rec. IEEE IAS Annu. Meeting, Edmonton, AB, Canada, 1-8.

[7] Schoen, R.R., Habetler, T.G., Kamran, F., Bartheld, R.G. (1995) Motor bearing damage detection using stator current monitoring. IEEE Trans. Ind. Appl., 31(6), 1274-1279.

[8] Thomson, W.T., Fenger, M. (2001). Current signature analysis to detect induction motor faults. Industry Applications Magazine, IEEE, 7(4), 26-34.

[9] Evaluation of measurement data. (2009). An introduction to the "Guide to the expression of uncertainty in measurement” and related documents, JCGM 104.

[10] Evaluation of measurement data. (2008). Guide to the expression of uncertainty in measurement, JCGM 100, GUM 1995 with minor corrections, First edition.

[11] Birch, K. (2001) Measurement Good Practice Guide, Estimating Uncertainties in Testing, An Intermediate Guide to Estimating and Reporting, Uncertainty of Measurement in Testing. British Measurement and Testing Association, 36, ISSN 1368-6550. 